\title{
A Study of Spice Trade from the Quanzhou Maritime Silk Road in Song and Yuan Dynasties
}

\author{
Cai-Zhen HONG ${ }^{1, a,{ }^{*}}$ \\ ${ }^{1}$ College of Applied Science and Technology, Quanzhou Normal University, Fujian, China, 362000 \\ a hongcaizhen2@126.com \\ * Cai-Zhen Hong
}

Keywords: Quanzhou; Maritime Silk Road; Song and Yuan Dynasties; Spice Trade

\begin{abstract}
The Chinese spice culture has a long history. After the An-Shi Rebellion, spice trade of the Western Region by the Land Silk Road was blocked, and the Maritime Silk Road started to play an important role. To Quanzhou Port in Song and Yuan Dynasties, the Maritime Spice Road can be considered as opposite direction of the Maritime Silk Road. At the end of Song and beginning of Yuan Dynasty, a large amount of spices were imported by Quanzhou and other areas in China, and Arabians had huge contribution on the trade. Among the most famous was Pushougeng who had monopolized for almost 30 years on Quanzhou foreign spice trade. Today's PuShi spice producer from Yongchun, Quanzhou is a heritage intermingling China spice culture and Arab spice production technology.
\end{abstract}

\section{Introduction}

China has more than two thousand years of history of sea transport of silk to overseas countries and tribes. It gains the "Maritime Silk Road" reputation from its descendants because of sea transportation. However, some scholars believe that in order to reflect the exchange cargo and goods structure changes, the word "silk" can be changed into other commodities. For example, China's exports in the Song Dynasty was changed to mainly ceramic products, and thus "Ceramic Sea Road" is more appropriate; in the Qing Dynasty, the export was mainly on tea, and "Maritime Tea Road" can be called; given that exports to Japan were mainly with books and culture, "Book Sea Road", or "Sea Road of Tang Poetry" should be called; some others also advocated use "Fragrant Sea Silk Road " and "Maritime Porcelain Incense Road." Actually, the most essential thing of the "Maritime Silk Road" is the sea route channel, not just exports of silk, but to exchange ambassadors, trade and cultural between ancient China and overseas countries. The sea lanes is bidirectional or multidirectional. It was named "Silk Road" because silk trade was the earliest and because of convention. Foreign merchant ships carrying pepper and spice and the formation of "Maritime Spice Road", can be understood as China being the starting point of the Silk Road on the sea in the opposite direction [1] (the "Maritime Spice Road" in this paper is not to replace the "Maritime Silk Road", but for convenience). Then, how the spice trade evolved? What is the overseas trade commodity structure at the splendor period in the Song and Yuan Dynasties? What position is the spice trade among all trades? (Due to limited space, this article only studies the Song and Yuan Dynasties). What was the route of Quanzhou spice trade in Song and Yuan Dynasties? What role did Quanzhou play in the spice trade? This paper attempts to answer these questions.

\section{Chinese Incense Culture}

China incense culture has a long history, and is known together with tea culture and flower culture as the three major cultural phenomena. The history of burning incense by Chinese ancestors can be traced back to the late Neolithic age, about 6000 years ago. Xiao Jun believes that the reasons of burning incense by ancestors are to offer sacrifices to Heaven, for mosquito repellent and exorcise of evil spirits. [2] Fu Jingliang pointed out that the incense culture began in the ancient, germinated in the pre Qin period, started in the Qin and Han Dynasties, grew in Six Dynasties, completed in the Sui 
and Tang Dynasties, flourished in Song Dynasty, and wide spread in the Ming and Qing Dynasties. From the ancient times to present, the incense has been developed for the ritual and life use.

Early ceremonial incense is mainly embodied in burning firewood and offerings (wine and grain offerings, etc.). Incense for life use has also a long history, as early as 4000-5000 years ago living supplies Tao Xunlu has emerged. In the pre Qin period, the use of perfume bag, vanilla had been popular. At the time of the Warring States sophisticated smoked furnace, Boshan furnace had been produced. In the early Emperor Wudi of Han Dynasty period (about 120 years BC), incense and incense burner had been popular in nobility in the north and south parts of the country; in the early Eastern Han Dynasty, incense is abundant and is regarded as a kind of enjoyment of life, a method of removing dirty health; in the Wei and Jin Dynasties incense had been used by the literati; in the Northern Song Dynasty "fragrance is among all lanes". Rich category of aromatic plants were used for incense, expelling worm, medical and health and many other fields, and were used by smoked burn, wear, smoke bath, and beverage service etc.. [3] Incense culture had become popular at that time.

From the spice origin perspective, in the pre Qin period, the earth climate was warm and cool, which was not suitable for the growth of plant spices, and border and overseas spice medicine (incense, sandalwood, frankincense) had not yet been imported from the mainland. Therefore, spice medicine was mainly from local vanilla and fragrant wood, such as orchid, irises, pepper, and cinnamon, etc. The vanilla uses were very rich at that time. It had been recorded by Classic books such as "the book of songs", "Shangshu", "book of Rites", "rites of Zhou", "Zuo Zhuan", etc. [4]

\section{The Maritime Silk Road and Spice Trade}

\section{China China Spice Trade Before the Sui and Tang Dynasties}

During the territory expansion of the Qin and Han Dynasties, "Land Silk Road" and "Maritime Silk Road" opened, a number of spices were introduced to China from South China, South Asia and Europe. Incense, sandalwood etc. had been popular among the nobility in the Han Dynasty. The prevalence of Buddhism and Taoism in the Han Dynasty promoted the development of incense culture. [5] The rapid development of the incense culture in Han Dynasty also had a great relationship with Emperor Wudi, who loves incense incredibly, which greatly boosted the incense market.

Before the Sui and Tang Dynasties, most of the best spices were from the offerings of other countries, and is a luxury in upper class, and is not popular in the middle and low classes. After the Tang Dynasty, the situation was completely different. A large number of spices were transported along the Silk Road across the Asian hinterland from the western regions to China. After the An-Shi rebellion north land Silk Road was blocked, south Maritime Silk Road began to flourish with ship building and navigation technology improvement. A lot of spices entered the north from Guangdong, Guangxi, and Fujian.

\section{The Maritime Silk Road and the Spice Trade in the Song and Yuan Dynasties}

Maritime technology in Song Dynasty was highly developed, the south "Maritime Silk Road" was more prosperous than the Tang Dynasty. Chinese exported goods were mainly gold, silver, copper, silk, porcelain, and imported goods were spice medicine, bead jade, ivory, and rhinoceros horn (see "history of the Song Dynasty" 186). [7] According to research, the import of the Song Dynasty spices amounted to tens of thousands of pounds per year, accounting for $1 / 4$ of the imported goods. [8] Incense, borneol, aloes and various spices from South Asia and Europe across the seas arrived in Guangzhou, Quanzhou and other southeast coastal ports, and then transferred to the mainland. At the same time, the fragrance of musk from China was shipped to South Asia and Europe. The Shibo department in Quanzhou was the management of import and export trade agency in Song Dynasty. The spice trade tax was the country's main financial income. In the Song Dynasty, the government even monopolized the spice trade, which was not allowed to trade without permission. [9]

Huang Chunyan summarized in Table 1 the imported goods in Song Dynasty: 
Table 1 Import Commodities in the Song Dynasty

\begin{tabular}{|l|l|}
\hline Type & Name \\
\hline Treasures & gold and silver, ivory, rhinoceros horn, hawksbill, pearl, coral, etc. \\
\hline Spices & incense, sandalwood, Benedict oak, benzoin, musk wood, etc. \\
\hline medicine & pepper, ginseng, musk, etc. \\
\hline Normal goods & silk cloth, some daily necessities cloth, silk, pine board, folding fan, etc. \\
\hline Military supplies & Japanese knife, iron, sulfur, knife, furs, etc.. \\
\hline
\end{tabular}

Source: Huang Chunyan. Song Dynasty overseas trade [M]. Beijing: Social Science Literature Press, 2003, 55

It can be seen from the above the important position of spices in the import trade of the Song Dynasty. In 1289 in Yuan Dynasty, nearly a hundred countries and regions had trade with Quanzhou. According to the "Yuan History", in April of ZhiYuan thirty years (1293), the Quanzhou Bureau of the imported goods charged 1/30 of the trade as tax, the lowest among all trade ports. Wang Dayuan, recorded that more than 90 kinds of goods exported through Quanzhou port, the vast majority are handicraft industrial products. A total of 90 kinds of foreign goods, as compared to "Zhu Fan Zhi", in addition to various types of clothing, food, Po goods, cloth fan, grocery, spices still is the main commodity. [11]

\section{The Spice Trade in Song and Yuan Dynasties in Quanzhou}

\section{Development of Three Major Ports in Southeast China in the Song and Yuan Dynasties}

Since the sea opening in Western Han Dynasty, Southeast China had more than ten ports related to Maritime Sea Road. Until the Song and Yuan Dynasties Guangzhou, Mingzhou (Ningbo), Quanzhou are the three largest trading ports. During the Northern Song Dynasty, Guangzhou's foreign trade volume had been an absolute advantage among the three largest trading ports. In the Song Dynasty, spice medicine, for example, Shenzong Xining ten years (1077), Guangzhou, Hangzhou, Mingzhou Port imported a total of 354,449 pounds, in which the Guangzhou port had 348,673 pounds, about $98.3 \%$ of the national total, Minzhou had 4,739 pounds, 2nd largest among the three major ports.

In the $2^{\text {nd }}$ year of Songzhezong (1087), the Shibo department was set up in Quanzhou. In the $2^{\text {nd }}$ year of Kaixi (1206), the number of overseas countries and regions that had trade with Quanzhou was 31, and quickly increased to 58 in 1225. At this time Quanzhou was the main Chinese customs, and Quanzhou port overseas trade entered its prime. [12]

\section{The Largest Port in the East- Quanzhou Citong Port}

Quanzhou people emphasize on trade from ancient times as evidenced by Xie Lv from Fujian Huian in Northern Song Dynasty had "Quan Nan Song". Since the trade, many people from Quanzhou have become rich. At the time of the Quanzhou folk overseas trade was rampant, thousands of sails raced in Citong port. Marco Polo said: "in Zayton (Quanzhou), the Indian merchant ship arrivals are frequent, imported spices and other goods, many Southern China businessmen came here. Countless beads and other products of foreign transport, all of which were distributed here into the south... Quanzhou port is one of the two largest trading ports in the world.[13]

"From eighth Century to fifteenth Century, Arabians had been leading the world trade. They came from the Persian Gulf through the India Ocean, the Malay Peninsula to Guangdong. Jiaozhou, Yangzhou and Fujian Quanzhou, had been the trade destinations of Arabs from the Tang Dynasty." [14] At the meantime, Islam was also introduced into China. According to the records of the Ming Dynasty, a famous local chronicle scientist He Qiaoyuan's "Minshu", Mohammed's disciples were buried in Quanzhou mountain of the eastern suburbs. From mid 13th century to mid 14th century, a large number of Arab and Persian Muslim businessmen flocked to Quanzhou, to build a mansion in the Quanzhou, open shops, build temples, and set up Fanfang. Tomb of their group can be seen 
everywhere outside the city area. [15]

\section{Pu Shougeng, Pu system Incense Heritage and Yongchun, China’s Incense Capital}

The development of Quanzhou Maritime Silk Road and spice trade benefited from the Arab traders, especially from an Arab descent, Pu Shougeng at the end of Song and beginning of Yuan Dynasty. Pu Shougeng (1245 -1284), was also named Hai Yun. He inherited his father, mainly engaged in overseas trade of bulk spices. "History of the Song Dynasty, the Ying Chronicles" contains: "Pu Shougeng, the head of Quanzhou Boshi, engaged in sea trade for 30 years", $\mathrm{Pu}$ Shougeng had great contribution to Quanzhou port development, as evidenced by the names related to Po Shougeng in Quanzhou, such as Wu Xiang, Xiangfo temple, etc. [17]

In Hui nationality with Surname Pu in Yongchun County, Quanzhou, a lot of people still follow the ancestral incense industry. Yongchun incense production process originated from $\mathrm{Pu}$; $\mathrm{Pu}$ incense production industry, was originated from the Maritime Silk Road, a prosperous spice route according to the Arabians. Pu Lianggong, descendant of Pu Shougeng, still has the old trademark seal in Yongchun Wuli Street "Pu orchid room". He is well aware of the incense, sandalwood, herb orchid scent and a variety of spices. His son Pu Haixing thinks their family tradition is the fusion of the China incense culture and Arab descent incense production technology for a thousand years. He has opened a spice shop in Taobao called "Yun Lutang", and also trains his daughter knowledge of incense. [18]

In May, 2014, China Light Industry Federation and the China daily goods industry officially awarded Yongchun Da Pu town "Chinese incense capital - Yongchun Da Pu" title, which is the only national incense base title in China. Da Pu town has a history of more than 300 years of incense, 296 incense companies, with a staff of nearly 30 thousand people. More than a dozen of incense enterprises have annual revenue above 20 million Yuan, including Binda, Xinglong, Jinfeng, Lianfa, etc., and more than 1100 kinds of products. In 2013 the incense industry has produced a total 2.7 billion Yuan in revenue, and sales network all over the country. They were also exported to Europe, Southeast Asia and other regions. Da Pu town, ancient city of Hebei, Qingyuan, Guangdong, and Xiamen Xiang'an are named "China's four biggest incense bases".

YongChun incense enterprises are based on maritime Silk Road culture, traditional Chinese medicine pharmacology, in the direction of culture return, and incense industry has gone beyond the traditional concept of worship activities, to home, health, cultural appreciation and higher level. They produced the linear incense and car incense device, a new type of incense products. The construction of incense industrial park is a key project of Fujian Province, the Da Pu Binda incense factory has opened the Binda Incense Culture Industrial Park. Traditional incense making process includes ten steps. In the simple and elegant incense Museum, you can experience the fun of "do it yourself" (DIY). A master will guide the visiting guests to experience the traditional process of incense, understanding of a long history of incense culture. [19] Incense culture tourism industry will be an important Yongchun incense enterprises marketing, which has attracted many tourists from Shishi, Jinjiang, etc.

\section{Quanzhou Spice Trade Route in Song and Yuan Dynasties}

From above, spice trade is actually the opposite of "Maritime Silk Road". In the late Southern Song Dynasty to the early years of the Yuan Dynasty, Quanzhou has become the base port to estimate navigable route distance, time and position between China and Southeast Asia, India, Arabia and North Africa. [20] The route between coastal areas and overseas countries can be divided into two major north-south directions, with north direction to Japan and Korea, and south direction to Southeast Asia, Arabia and East Africa and other places. The route to the south is the main route of the spice trade. The route to the southeast is from Guangzhou and Quanzhou, via the east of Hainan Island Ocean.

The route to the South Asia, West Asia, and Africa is also a main route of the spice trade. It takes more than 20 days from Lanwuli in southeast Asia to Xilan ("Zhufanzhi” volume I). Along India Ocean to the west are countries along the southern coast of India. From the Persian Gulf port on the 
Arabia Peninsula can get into the Red Sea, and to the south to East Africa. [21]

In Zhiyuan 26 years (1289), nearly a hundred countries and regions had trade to Quanzhou. Wang Dayuan "Dao Yi Zhi Lue" recorded those countries including 21 central south Peninsula, 40 Nanyang islands, 28 Indian peninsula, 14 Arabian Peninsula, 11 northeast Africa countries, and 3 East Asia countries. The total number far exceeded 31 from Zhao Yanwei's "Yunlu ManChao", or 58 from Zhao Rushi's "Zhu Fanzhi". Except the 3 countries in East Asia, other regions are the main producing areas of spices. In Yuan Dynasty, Quanzhou was engaged in spice trade with these countries.

\section{Acknowledgement}

This paper is funded by Quanzhou Normal University of the third batch of academic leaders training project, cultural research center of Chinese Academy of Social Sciences Southern Fujian culture research base (Quanzhou Normal University) project.

\section{References}

[1] Shi Cunlong, Several important problems study on "Maritime Silk Road" theory [A]. Lin Liqun, Across the Ocean "Marine Silk Road and world civilization "international academic forum anthology [C]. Hangzhou: Zhejiang University Press.2011:19-22.

[2] [4] [8] Xiao Jun, The origin of Chinese incense culture [J]. Journal of Yangtze University (SOCIAL SCIENCE EDITION).2011 (9): 168-169.

[3] Fu Jingliang, China Incense Culture [M]. Ji'nan: Qilu Press.2008: introduction 3-5.

[5] [9] Knife of Sanshao. Chinese incense culture evolution process [J]. Tea Exposition.2012 (7): 39-42.

[6] [7] [10][13][14] [17] Sangyuanzhizang, Chen Yujing. Pu Shougeng study [M]. Beijing: Zhonghua Book Company.2009:4, 23, 2-3, 25-28, 1-2, 150-151.

[11][12] Sea Silk Road (yuan) [EB/OL]. Quanzhou history website (2015-7-20).Http://qzhnet.dnscn.cn/qzh199.htm.

[15] The biggest port in the East [EB/OL]. (2015-7-20).

http://baike.baidu.com/link?url=czN8S6x1ZuxO3skabh15ojtq43U5w51p4WZ2gvMwuYLtTMzJ_F SK5BTUxH0olpoyi8uFS74_4Gf0JGG0exZ7dq

[16] From Arabia to Citong city [N]. Strait Metropolis Daily, (2014-6-11, A2.)

[18] Quanzhou and the Arab has millennium sentiment, Arab left footprints everywhere. Quanzhou network,(2014-06-17).Http://www.qzwb.com/spec/content/2014-06/17/content_4996609_3.htm..Ht tp://www.qzwb.com/spec/content/2014-06/17/content_4996609_3.htm..Http://www.qzwb.com/spec /content/2014-06/17/content_4996609_3.htm.

[19] Yongchun Dapu will be listed as "Chinese incense capital", worship incense turns into home health incense [EB/OL]. (2014-06-11) http://www.mnw.cn/.

[20] Li Jun. Comparative study among Guangzhou, Mingzhou (Ningbo) and Quanzhou port development during the boom of "Maritime Silk Road" in the Song and Yuan Dynasties [J]. Southern heritage, 2005 (1): 76-82.

[21] Huang Chunyan. Song Dynasty overseas trade [M]. Beijing: Social Science Literature Press.2003:237-238. 